\title{
Research of Greenhouse Control System Based on Fuzzy Math
}

$$
\text { Lei } \mathrm{XiaO}^{1, \mathrm{a}} \text {, Li Li }{ }^{2, \mathrm{~b}^{*}} \text { and Xiaolong } \mathrm{Wu}^{3, \mathrm{c}}
$$

${ }^{1}$ Institute of Teaching and Research of Ideological and Political Theory, Kunming University, Kunming, 650214, China;

${ }^{2}$ Pan-Asia Business School, Yunnan Normal University, Kunming, 650092, China;

${ }^{3}$ Faculty of mechanical and electrical engineering, Kunming University of Science and Technology, Kunming 650500, China;

a391644664@qq.com, bleisurelily@qq.com, cwx16895209@126.com

Keywords: Fuzzy Math, Logic Controller, Greenhouse System, Matlab

\begin{abstract}
Advanced greenhouse technology determines the pace of development in agriculture. However, because of differences in the region, our country is still a higher operating cost in the agriculture field, personnel technical ability is not higher factors and the popularity of intelligent greenhouse is not high, have a direct impact on the level of China's agricultural science and technology. In order to developing of our country's agricultural science and technology better, so it is particularly important to the development of intelligent greenhouse. This paper will describe that the fuzzy mathematics is used to realize greenhouse real-time control. And some reasonable fuzzy mathematics control rules are found by computer simulation in Matlab. Then the real-time controller will be applied by fuzzy control rules with Programmable Logic Controller (PLC) circuit and host computer $[1,2]$. At last, writer made a conclusion that debugging greenhouse real-time system is well to meet the requirements of greenhouse.
\end{abstract}

\section{Introduction}

In greenhouse control system, undeveloped control technology couldn't meet modern agriculture requirement, so a new intelligent control technology must be research to solve this problem. Automation control system can decrease the stability of controller and improve productivity, this is a signal of modern management, also is the development direction and trend of the modern agriculture. Currently, some greenhouse control system still depends on decision of human experience to control the time and manner of operation [3, 4]. But the real time and effectiveness of system are unreasonable to ensure, this phenomenon must be changed, then a more reasonable control manner should be used, so using the information of computer-aided analysis to accuracy control greenhouse environment is a valid way to increase the stability of controller.

At present, greenhouse control hardware system usually is SCM or IPC [4-6]. Although SCM control system is cheaper than other control system, it has heavy interference in the process of operation. The price of the IPC and computer as lower machine is a little expensive, and its' function can't be realized fully. And these control system don't detection to the information of computer-aided analysis, it could cause unreasonable control and decrease productivity. This paper comes up with a manner is that PLC as control core to research and using fuzzy control technology to realize control environment factor in greenhouse, it will decrease our costs and increase efficiency.

\section{Fuzzy control strategy design}

In fuzzy control, fuzzy controller as whole control system core, its' set up based on human experience, and these experience don't depend on Precise mathematical model. Now an example of the irrigation system will be illustrated, the characteristics of the seedling water is very difficult to make model, so the irrigate control can realize by fuzzy control rules. The design process is as below: 


\section{Determine fuzzy controller Input and output variables.}

In irrigate control system, farmland owned water is usually as irrigate critical point. Excessive water, full water, moderate water shortage and a serious lack of water as a standard to judge the water supply situation based on experience of the quota irrigation. a serious lack of water is bad to plant growth, moderate water shortage will increase regulating function of the plant, plant nutrient excessive consumption will be limited. And growth potential of plants will increases, the efficiency of water will also increase. In this control system, $\mathrm{W}$ as input variables is the difference of water (the difference of soil moisture and farmland owned water), $\triangle \mathrm{W}$ is the change rate of moisture (the change trend of the moisture) and output variables is supply time $t$.

\section{Solve fuzzy control table.}

Because the shape of fuzzy centralize membership functions hasn't impact to controller, and the discover area size of every fuzzy subset membership functions has a big impact to fuzzy controller. This paper will makes use of triangular and trapezoidal as the shape of membership functions, select five language value as input and output variables: PB, PS, ZE, NS, NB. To difference of water $W$, supply water will not be considered in excessive and full water supply, so difference of water $W$ will only selects three language variables: NB (severe water shortage), NS (water shortage), ZE (moderate water shortage); The change rate of owned water rate will selects five language variables: NB (severe water loss), NS (water loss), ZE (Unchanged water), PS (a little increase water), PB (a lot increase water); The time of supply water $t$ will selects three language variables: ZE (no water supply),PS (short supply), PB (long supply). Based on actual experience, the reasonable moisture lower limit of crops is $65 \%$ $75 \%$ of the farmland owned water. In this paper, farmland owned water will selects $[6,10]$ as the size of soil moisture, the difference of soil moisture $W$ is $[-4,0]$, the change rate of owned water rate $\Delta W$ is [-4 , 4], the size of supply water time $t$ is $[0,10] \mathrm{min}$. After normalization, the membership functions of fuzzy subset $(u(W), u(\Delta W), u(t))$ need be determined on the area of each language variable, shown in figure.1.

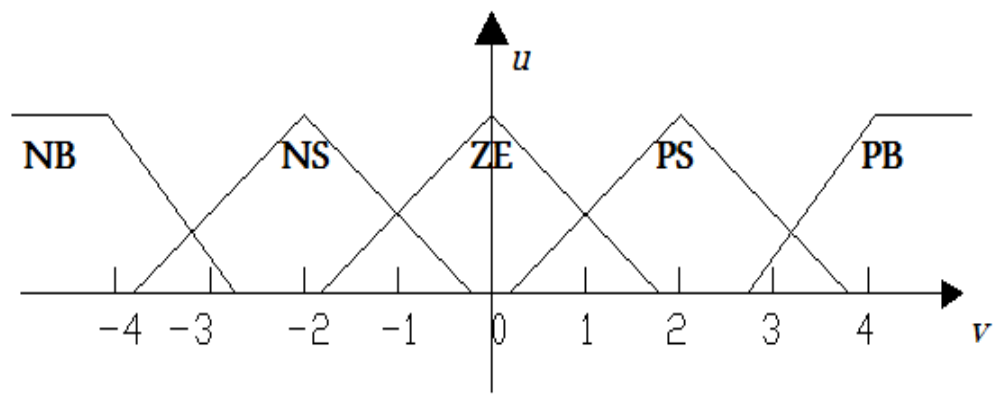

Fig.1 Fuzzy definition of inputting and outputing variables.

According to the definition of every fuzzy quantity, fuzzy evaluation value table can be found in table.1.

Table 1. Fuzzy evaluation value table of $\mathrm{W}, \Delta \mathrm{W}$ and $\mathrm{t}$

\begin{tabular}{|c|c|c|c|c|c|c|c|c|c|}
\hline$W, \Delta W, t$ & -4 & -3 & -2 & -1 & 0 & 1 & 2 & 3 & 4 \\
\hline NB & 1 & 0.333 & 0 & 0 & 0 & 0 & 0 & 0 & 0 \\
\hline NS & 0 & 0.463 & 1 & 0.463 & 0 & 0 & 0 & 0 & 0 \\
\hline ZE & 0 & 0 & 0 & 0.333 & 1 & 0.333 & 0 & 0 & 0 \\
\hline PS & 0 & 0 & 0 & 0 & 0 & 0.463 & 1 & 0.333 & 0 \\
\hline PB & 0 & 0 & 0 & 0 & 0 & 0 & 0 & 0.333 & 1 \\
\hline
\end{tabular}

In fuzzy control, determine fuzzy rules is a very important and complex thing, its' formulation is based on worker experience. In this study, fuzzy control rules will use the structure mode: IF...AND...THEN. Based on some expert experience, this system need twenty-five fuzzy control rules, then makes use of computer simulation technology to optimize the twenty-five rules, makes them simplified fifth rules, and compute out fuzzy control status table, these data is shown in table.2 . Fuzzy control table will be found by computer. This information is shown in table.3. In fuzzy control, based on the control table, then look-up table find the domain value of output control 
value, then makes output value multiplied by a scale factor for solving actual control quantity to realize control objection.

Table 2. Fuzzy controlling state table

\begin{tabular}{|c|c|c|c|c|c|}
\hline$W, \Delta W, t$ & NB & NS & ZE & PS & PB \\
\hline NB & PB & PB & PS & PS & ZE \\
\hline NS & PB & PS & PS & ZE & ZE \\
\hline ZE & PS & ZE & ZE & ZE & ZE \\
\hline
\end{tabular}

Table 3. Fuzzy controlling table

\begin{tabular}{|c|c|c|c|c|c|}
\hline$W, \Delta W, t$ & -4 & -2 & 0 & 2 & 4 \\
\hline-4 & 4 & 4 & 2 & 2 & 0 \\
\hline-2 & 4 & 2 & 2 & 0 & 0 \\
\hline 0 & 2 & 0 & 0 & 0 & 0 \\
\hline
\end{tabular}

\section{Simulation.}

For verifying above fuzzy control rules meet requirements, computer simulation can achieve conclusion, it can decrease experiment time, save price of the experiment. This paper makes use of the data of table.3 with Matlab software to simulate, then the surfaces of input and output be found, it's shown in fig.2. In fig.2, when the difference of water $W$ is -4 and the change rate of owned water $\Delta W$ is -4 , the output value $t$ is 4 , this mean that crops need irrigate 4 minutes. The result almost meets the data of the table.3.

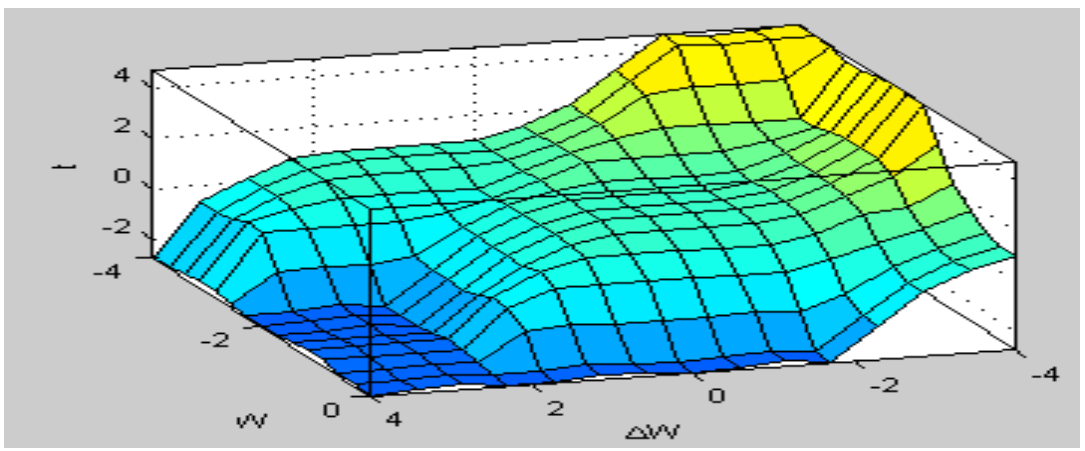

Fig.2 Plot of input and output

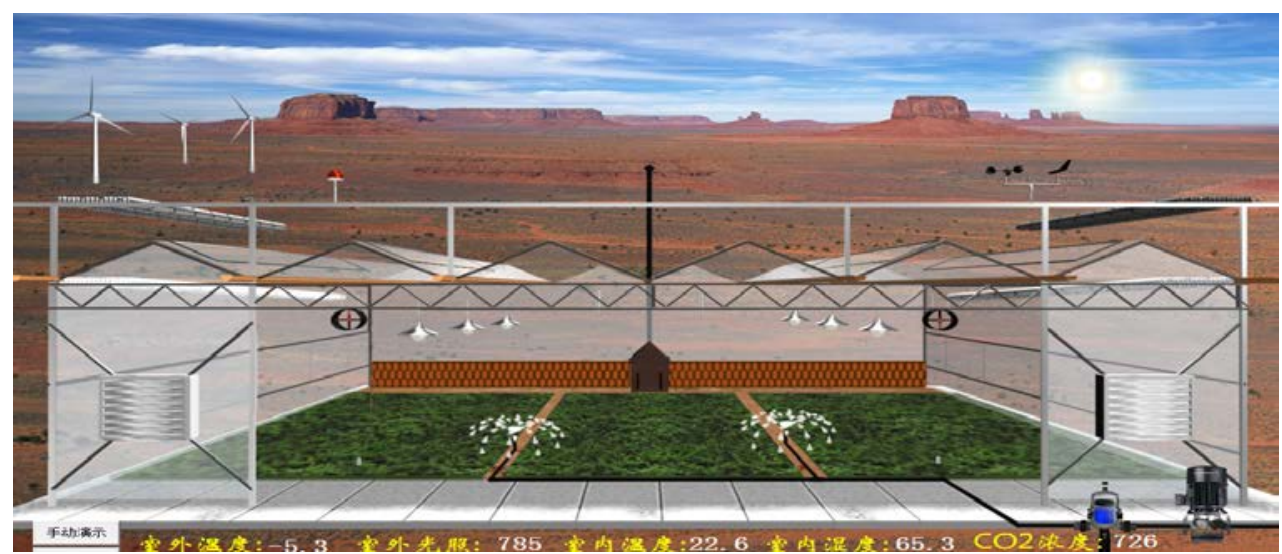

Fig.3 The interface of Greenhouse system

\section{Control system software design}

This control system software includes three parts: PLC control program, PC control program and communicate program. As whole control system underlying unit, PLC plays an important role on collecting and dealing with system data. After PLC collects the data of soil moisture, it converts these data from analog-to-Digital value. Then new data will be dealt to realize irrigate function by 
fuzzy control technology. This system software makes use of KingView. When designing system, it design PC main interface in order to facilitate the user's actions.

In actual using, PC and PLC should communicate data directly in time and be monitoring in long distance, so that selecting MSComm program to realize communication.

\section{Debugging control system running}

According to above describe, experimental prototype is produced. Above control rules was sent to prototype, then all test point began to measure soil owned rate, the farmland owned water was found exceed 0.9. So this control system is able to keep soil owned water rate value of 0.9. To excellent greenhouse seedlings, monitoring and counting their growth data find them in good shape and no water shortage in two thousand seedlings samples.

\section{Conclusion}

This paper uses Siemens PLC to realize the function of control system, and uses PC to realize the function of upper machine. The control program of lower machine select ladder language to write, and the interface and data transfer module of upper machine makes use of KingView to write program. Control system builds fuzzy control strategy and control hardware circuit based on user's requirement and fuzzy mathematics. After actual running, the real-time and reliability of this system is very good, it can meet need of seedling. And operate manner of this control system is very easy, it can increases real-time, reasonable, scientific and economic gains of greenhouse system management in production.

\section{Acknowledgements}

This research is supported by Philosophy and Social Science Research Base Project of Yunnan Province (JD13ZD09).

Corresponding Author: Li Li, PHD, Pan-Asia Business School, Yunnan Normal University. Email: leisurelily@qq.com

\section{References}

[1] Wael M. El-Maghlany, Mohamed A. Teamah, Hiroshi Tanaka: Energy Conversion and Management, Vol.105 (2015), p.1096-1104

[2] Reinier A.C. van der Veen, Julia Kasmire: Energy Policy, Vol.87 (2015), p.8-16

[3] Eric Taylor: Journal of Public Economics, Vol.117 (2014), p.162-181

[4] Spyros G. Tzafestas: Introduction to Mobile Robot Control, Vol.20 (2014), p.269.

[5] Albert W.L Yao and C.H Ku: Electric Power Systems Research, Vol.64 (2003) p.129.

[6] I. Salgado, O. Camacho, C. Yáñez, I. Chairez: Engineering Applications of Artificial Intelligence, Vol.35 (2014) p.84. 